\title{
A DIFFUSIVE-WAVE BASED HYDROLOGIC-HYDRAULIC MODEL WITH SEDIMENT TRANSPORT I: MODEL DEVELOPMENT
}

López-Barrera D. ${ }^{1}$, García-Navarro P. ${ }^{2}$, Brufau P. ${ }^{3}$ and Burguete J. ${ }^{4}$

${ }^{1}$ (corresponding author)

Fluid Mechanics, C.P.S., University of Zaragoza,

Edif. Torres Quevedo, C/ María de Luna 3, 50018 Zaragoza (Spain)

e-mail: danilopezgbarrera@hotmail.com

Tf.: +34 9761000 ext. 5052

Fax: +34976761882

${ }^{2}$ Fluid Mechanics, C.P.S., University of Zaragoza,

Edif. Torres Quevedo, C/ María de Luna 3, 50018 Zaragoza (Spain) e-mail: pigar@unizar.es

Tf.: +34 9761000 ext. 5056

Fax: +34976761882

${ }^{3}$ Fluid Mechanics, C.P.S., University of Zaragoza,

Edif. Torres Quevedo, C/ María de Luna 3, 50018 Zaragoza (Spain) e-mail: brufau@unizar.es

Tf.: +34 9761000 ext. 5051

Fax: +34976761882 


\author{
${ }^{4}$ Fluid Mechanics, C.P.S., University of Zaragoza, \\ Edif. Torres Quevedo, C/ María de Luna 3, 50018 Zaragoza (Spain) \\ e-mail: jburguete@eead.csic.es \\ Tf.: +34 9761000 ext. 5048 \\ Fax: +34 976761882
}

\begin{abstract}
$\underline{\text { Abstract }}$
In this paper, a distributed numerical model is proposed based on: (1) A hydrologic model for the water exchange laws. (2) A surface runoff model based on a suitable 2D formulation that behaves as the diffusive model for zero or adverse slopes and the kinematic wave otherwise able to calculate flow over all kind of wet/dry bed slopes. (3) A groundwater flow model based on the 2D Darcy law for both saturated and partly saturated zones. (4) A 2D Hillslope Erosion Model for the sediment transport. (5) An explicit finite volume discretization with specific schemes according to the flow equations characteristics, upwind for the hyperbolic equations and centered for the parabolic equations. The resulting model offers a variable time step ensuring numerical stability with a time step size sensitive to the grid cell size in the diffusive wave case and an entropy correction of the upwind fluxes to ensure conservative solutions near local maxima in the slopes controlling the water movement. The validation and practical application of the model is presented in a companion paper in which the potential usefulness of the proposed model is demonstrated.
\end{abstract}

Keywords: Kinematic-wave. Diffusive-wave. Finite volumes. Upwind schemes. Hillslope erosion model. Hydrologic model. Hydraulic model. 


\section{$\underline{\text { Introduction }}$}

The development of predictive hydrologic-hydraulic models is justified since they can be a useful tool to achieve a plan of integral management of basins from the point of view of water resources, flood prevention, irrigation and drainage. A good balance among predictive capability, computational cost, data requirements and sensitivity to the model parameters must be a fundamental aim.

Historically, lumped hydrologic models based on empirical or tuneable parameters have been used to calculate the runoff discharge (ASCE, 1996; Mays, 2001). These models based on empirical laws are widely used because of their simplicity and low computational cost. However, due to the advances in the computing power, in the last two decades many distributed models based on physical-based laws to simulate the water movement between the cells in which the basin is divided have been developed. These models are usually based on Kinematic-wave (KW) and Diffusive-wave (DW) approximations of the depth average flow equations due to the expectable advantages that they could offer in terms of computational cost with respect to the complete Saint-Venant model (Mahmood and Yevjevich, 1975; Wasantha Lal, 1998; Hunter et al., 2005; Kazezyilmaz-Alhan and Medina, 2007; Yu and Lane, 2007; Prestininzi, 2008; Moramarco et al., 2008; Moussa and Bocquillon, 2009). Examples of the KW and DW models are MIKE SHE (Abbot et al., 1986), WEP (Jia et al., 2001), tRIBS (Ivanov et al., 2004), InHM (Heppner et al., 2006) and other simplified models such as TOPMODEL (Beven and Kyrkby, 1979) or ANSWERS (Beasely et al., 1980). In these models a Strickler / Manning-type law is usually applied for the friction slope calculation or by means of even more simplified assumptions such as making the flow proportional to the bed slope (Beven and Kyrkby, 1979). Then, the surface runoff model is often combined with semi-empirical laws to model the infiltration, the exchanges between 
sub-surface reservoirs and to simulate the groundwater flows.

In this context, the model presented here has been designed paying special attention to the mathematical properties of the equations governing the overland flow in the KW and DW models in order to use an appropriate discretization scheme. Therefore, our work is devoted to get a deep understanding of the mass conservation and numerical stability constraints. A finite volume explicit upwind scheme has been developed on rectangular meshes for this purpose. Both the KW and DW models can be written in the form of a volume conservation law, the main difference being the slope that governs the water discharge. For that reason, in this work, the two models KW and DW have been considered together with a third option written from their combination, the Extended Kinematic Wave model (EKW). They can all be solved by using a conservative explicit upwind finite volume scheme.

The KW model is retained as a reference since it enables the analysis of the numerical stability conditions for the application of this scheme and offers the possibility to evaluate an exact stability condition. From this point, the stability limits of the numerical scheme when applied to the DW equation model can be explored.

Additionally, the surface flow models are combined with simple laws to simulate the evapotranspiration, the infiltration and the exchanges between sub-superficial and groundwater flows and the bed. The model is completed by a 2D subsurface and groundwater flow based on a Darcy approximation. Although more complex laws could be used to simulate these processes (Morita and Yen, 2002), the lack of information available in real basins makes that effort not efficient. A centered explicit scheme has been used to discretize the groundwater and non-saturated flows. The global model time step size is controlled by the most restrictive stability condition. In our experience, this is imposed by the overland flow submodel.

The proposed model is also able to simulate sediment transport phenomena by using a 
2D extension of the Hillslope Erosion Model (HEM) (Lane et al., 1995; Prosser and Rustomji, 2000; Shyrley and Lane, 1978; Harmon and Doe III, 2001; Wigmosta et al., 2009).

\section{$\underline{\text { The mathematical models }}$}

Real basins water content has been usually divided in three main zones: Surface water, unsaturated zone water and groundwater (ASCE, 1996; Mays, 2001; Brustraert, 2005). Figure 1 shows a schematic view by means of the vertical distribution where the water storage in each zone has been represented by a water depth. In the case of the surface zone, $h$ represents the water depth. In the case of the non-saturated and groundwater zones, $h_{n s}$ and $h_{s a t}$ are a representation of the water content being $h_{\text {sat }}$ associated with the water table level and $h_{n s}$ the water depth equivalent to the water content in the partially saturated zone. The notation $h_{\text {sat, }}$ $h_{n s}$ stands for water pressure head as used in Darcy's law. However, it also represents water column length in unconfined conditions Heppner et al. (2006) have reported a comprehensive physics-based hydrologic-response model with solid transport that is comparable to the model presented here in the hydrologic response part. The model presented by Heppner et al. (2006) includes also a component dealing with the individual response of different bed material species to the erosion agents.

Figure 1: Schematic representation of the model levels.

\section{Evapotranspiration, Infiltration and Percolation}

In this work the evapotranspiration (ASCE, 1996) is considered as a water loss effect modelled via Hargreaves method $E T_{0}=0.0135\left(t_{\text {mid }}+17,78\right) R s$, where $E T_{0}$ is the daily 
potential evapotranspiration in $\mathrm{mm} /$ day, $t_{\text {mid }}$ is the daily average temperature in ${ }^{\circ} \mathrm{C}$ and $R s$ is the solar incident radiation, converted into mm/day (Hargreaves and Samani, 1985; Samani, 2000). The incident solar radiation, $R s$, is evaluated from the extraterrestrial solar radiation (Samani, 2000). The real basin evapotranspiration capacity is calculated by application of the correction factor proposed by Michel (1989). This water loss is based on water availability. The events considered are all driven by precipitation and the model calculates the effective rain that arrives onto the soil $P e(x, y, t)$ by subtracting from the total precipitation $P(x, y, t)$ the water lost by evapotranspiration.

The Green-Ampt and the Horton formulae (Chow et al., 1994; ASCE, 1996) have been used to simulate the infiltration process. The basic assumption of the Green-Ampt equation is that the saturated hydraulic conductivity $k_{S 0}$ remains constant. The second assumption is that, when the model is applied to rainfall-runoff events where the surface water depth can be considered small, the influence of depth of pounding at the surface can be neglected.

Under those assumptions, applying Darcy's law between the soil surface and the humid front the Green-Ampt rate equation is (Chow et al., 1994; ASCE, 1996):

$$
i=\min \left[i_{\max }, k_{S 0}\left(\frac{\Psi M}{F}+1\right)\right]
$$

where $k_{S O}$ is the hydraulic saturated conductivity of the soil, $M$ is the initial moisture deficit in the soil calculated as the difference between the soil humidity state and the soil maximum potential humidity and $F$ is the accumulated infiltration depth. $\Psi$ is the effective suction at the wetting front (in m). Equation (2.1) is an extension of the classical Green-Ampt formula where the maximum infiltration rate $i_{\max }$ is a limit, dependent on the soil characteristics, proposed to provide a reasonable estimation in nearly dry conditions. 
Horton formula (Gupta, 2008; Bedient et al., 2008) estimates the infiltration rate as a function of time with three parameters:

$$
i=i_{c}+\left(i_{0}-i_{c}\right) \cdot e^{-k \cdot \tau}
$$

where $i_{0}$ is the initial infiltration rate, $\tau$ is the opportunity time or the time that the cell has been wet, $i_{c}$ is the constant infiltration rate achieved at large opportunity times and $k$ is a decay constant.

From the infiltrated water a part percolates to deeper zones (Chow et al., 1994). In our model, the amount of percolated water every time step $\Delta t$ is evaluated as:

$$
p=\min \left(F, \Delta t C_{p}\right)
$$

where $p$ is the percolated water depth and $C_{p}$ is the maximum soil percolation. $C_{p}$ is a parameter that includes both the primary and the secondary permeability (microporosity and macroporosity effects) (Chow et al., 1994).

More complex forms of coupling the overland and subsurface flows have been used by other authors (Morita and Yen, 2002). However, the lack of information about initial and boundary conditions about the groundwater suggest that an approximate solution like the one presented here may be appropriate.

\section{Surface flow}

Three models are proposed to simulate the surface water movement in this work: the Diffusive wave model (DW), the Kinematic wave model (KW) and the Extended Kinematic 
wave model (EKW).

It is well known that there are restrictions in the applicability of the $\mathrm{KW}$ model to real problems due to the fact that discharges are governed by the bed slopes. When there is not bed slope or when the bed slope is locally adverse, the model is unable to simulate correctly the problem. To extend the application range of the KW model a new formulation is proposed.

Defining $\boldsymbol{S}=\left(S_{x}, S_{y}\right)$ as:

$$
S_{x}=-\frac{\partial\left(z_{b}+m h\right)}{\partial x}, \quad S_{y}=-\frac{\partial\left(z_{b}+m h\right)}{\partial y}
$$

Both models (KW and DW) can be represented in a single form according to the value of the factor $m(0 \leq m \leq 1)$.:

$$
\frac{\partial h}{\partial t}+\nabla \cdot\left(\frac{h^{5 / 3}}{n \sqrt{|\boldsymbol{S}|}} \boldsymbol{S}\right)=\frac{\partial h}{\partial t}+\nabla \cdot \boldsymbol{q}=P e-i
$$

when $m=0$ the KW model is recovered, when $m=1$ the DW model is recovered. The EKW is based on a local definition of the value of $m$ at the computational grid edges where the KW approximation fails is proposed.

\section{The sediment transport model}

The Hillslope Erosion Model (HEM) (Shyrley and Lane, 1978; Lane et al., 1995; Prosser and Rustomji, 2000; Harmon and Doe III, 2001; Wigmosta et al., 2009) is a simple, robust model that was developed to estimate erosion and sediment yield at the hillslope scale. 
This model is a combination of the KW equations for overland flow and the sediment continuity equation. The model was developed specifically for hillslopes and was tested, evaluated and parameterized primarily for rangeland applications. Although the HEM may be less powerful than other more complex ones (Heppner et al., 2006), it is based on relatively few parameters related to the steepness, soil erodibility and vegetative canopy cover.

In our model, HEM is extended to $2 \mathrm{D}$ flows and incorporated to the three overland flow models described. The model is assumed governed by the sediment continuity equation for overland flow:

$$
\begin{gathered}
\frac{\partial(c h)}{\partial t}+\nabla \cdot(c \boldsymbol{q})=E_{i}+E_{r} \quad, \quad \boldsymbol{q}=(h u, h v) \\
E_{i}=K_{i} P e \\
E_{r}=K_{r}\left(\frac{n B}{\sqrt{|\mathbf{S}|}}-c\right) q
\end{gathered}
$$

where $c$ is total sediment concentration in $\mathrm{kg} / \mathrm{m}^{3}, E_{i}$ is interrill erosion rate per unit area in $\mathrm{kg} \cdot \mathrm{s}^{-1} \cdot \mathrm{m}^{-2}$, and $E_{r}$ is net rill erosion or deposition rate per unit area in $\mathrm{kg} \cdot \mathrm{s}^{-1} \cdot \mathrm{m}^{-2} \cdot K_{r}$ is the rill erosion coefficient in $\mathrm{m}^{-1}, K_{i}$ is the interrill erosion coefficient in $\mathrm{kg} / \mathrm{m}^{3}, B$ is a transportcapacity coefficient in $\mathrm{kg} \cdot \mathrm{s}^{-1} \cdot \mathrm{m}^{-8 / 3}, n$ is the Manning roughness coefficient and $q$ is the modulus of the unit discharge $q=\sqrt{q_{x}^{2}+q_{y}^{2}}=\sqrt{(h u)^{2}+(h v)^{2}}$. The discharge is a function governed by the slope corresponding to the selected overland flow model (KW or DW).

Field data are used to calibrate the model parameters $B, K_{r}$ and $K_{i}$ and to relate them to the soil properties, slope length and steepness, vegetative canopy cover and ground surface 
cover (Russell et al., 2001). A regression analysis of the data published by Russell et al. (2001) yielded an internal relationship between $B$ and the slope $S_{0}=\sqrt{S_{0 x}^{2}+S_{0 y}^{2}}$ as:

$$
B=B_{0}\left(0.088 S_{0}^{2}+0.1306 S_{0}-0.053\right)
$$

where $B_{0}\left(\right.$ in $\left.\mathrm{kg} \cdot \mathrm{s}^{-1} \cdot \mathrm{m}^{-8 / 3}\right)$ depends on the soil properties, slope length and vegetation cover.

It must be noted that the tabulated (Lane et al., 1995; Russell et al., 2001) values of the parameters $\left(K_{r}, B, K_{i}\right)$ are adjusted for the KW surface flow model $(m=0)$.

As the erosion and deposition processes $E_{i}$ and $E_{r}$ that produce the contribution to the solid mass conservation equation take place mainly in rills and formations that are not usually defined in the calculation meshes used in the model, the net change in the topography caused by erosion and deposition will not affect seriously the calculation mesh (Lane et al., 1995). Therefore, no morphological changes are considered in this model.

\section{Groundwater and unsaturated zone flows: The Darcy law}

Darcy's law (Chow et al., 1994) relates the velocity of water in saturated soils $\boldsymbol{v}_{\text {sat }}$ with the hydraulic potential gradient. Then, with reference to figure 1 , if $k_{S 0}$ is the saturated hydraulic conductivity, the flow velocity in the saturated zone can be expressed as:

$$
\mathbf{v}_{s a t}=-k_{S 0} \nabla\left(z_{h}+h_{s a t}\right)
$$

This law can also be applied to unsaturated cases by using a non-saturated hydraulic conductivity that is highly dependent on the soil water content. 


$$
\mathbf{v}_{n s}=-k_{S} \nabla\left(z+h_{e}\right)
$$

$z$ being the vertical position and $h_{e}$ the soil matric head (Brustraert, 2005). If an exponential distribution of the humidity in the soil is assumed, the effective hydraulic conductivity can be expressed as (Beven and Wood, 1983; Brustraert, 2005):

$$
k_{S}(z)=k_{S 0} e^{-f z}, \quad z_{h}+h_{s a t}<z<z_{b}
$$

where $f$ is a constant characteristic of the soil $\left(\mathrm{m}^{-1}\right)$. In the present model, an effective $k_{S}$ value is calculated as:

$$
k_{S}=\frac{\int_{z_{h}+h_{\text {sat }}}^{z_{b}} k_{S 0} e^{-f z} d z}{\int_{z_{h}+h_{\text {sat }}}^{z_{b}} d z} \approx \frac{\sum_{n=1}^{N} \frac{z_{b}-\left(z_{h}+h_{s a t}\right)}{N}}{z_{b}-\left(z_{h}+h_{\text {sat }}\right)}=\frac{\sum_{n=1}^{N} k_{S 0} e^{-f z_{n}}}{N}
$$

where $N$ is a number of divisions of the unsaturated zone (figure 2).

Assuming a thin unsaturated layer, the application of the Darcy law for the horizontal movement in this zone can be considered governed by the bed slope (Beven, 1986).

$$
\boldsymbol{v}_{n s}=-k_{S} \nabla z_{b}
$$

Figure 2: Schematic representation of the effective non saturated hydraulic conductivity calculation $(N=11)$. Left: Continuum and discrete water exponential distribution. Right: Effective unsaturated hydraulic conductivity. 
Darcy law is combined with the $2 \mathrm{D}$ depth averaged continuity equation:

$$
\begin{gathered}
\frac{\partial h_{s a t}}{\partial t}+\nabla \cdot \mathbf{F}_{s a t}=\frac{\partial h_{s a t}}{\partial t}-k_{S 0} \nabla \cdot\left[h_{s a t} \nabla\left(z_{h}+h_{s a t}\right)\right]=p \quad \text { for the satur } \\
\frac{\partial h_{n s}}{\partial t}+\nabla \cdot \mathbf{F}_{n s}=\frac{\partial h_{n s}}{\partial t}-k_{S} \nabla \cdot\left(h_{n s} \nabla z_{b}\right)=i-p \quad \text { for the unsaturated level }
\end{gathered}
$$

\section{Discretization of the equations}

A finite volume method has been chosen to solve the governing equations. The physical domain is discretized in rectangular cells for the easier connection with GIS based applications.

In each time step $\Delta t$, the water depth in each zone changes due to all of the above described processes. In our model, the influence of rainfall, infiltration and percolation are considered first before the 2D surface, subsurface and groundwater flows are evaluated. Figure 3 shows a flow chart of the model.

Figure 3: Flow chart for the computational model.

\section{Precipitation, infiltration and percolation discretization}

The connection between the different zones (surface flow, unsaturated zone and saturated zone) in the model is driven through the definition of interchange laws describing infiltration/exfiltration and percolation processes. The effect of the effective precipitation 
$P e(x, y, t)$ and the infiltration $i(x, y, t)$ in the model are implemented as source terms in the equation of overland flow (C.1). The non-aturated flow equation (2.16) is affected by infiltration and percolation rate $p(x, y, t)$ and the groundwater flow is affected by percolation processes. Sediment transport is also affected by precipitation effects. All these terms represent contributions (positive or negative) to the water content and sediment concentration of a cell $\Omega_{i, j}$ and are modelled in an explicit way as:

$$
\begin{gathered}
h_{i, j}^{n}-h_{i, j}^{0}=\max \left[(P e-i)_{i, j} \Delta t,-h_{i, j}^{0}\right] \\
\left.h_{n s i, j}^{n}-h_{n s i, j}^{0}=\max \mid(i-p)_{i, j} \Delta t,-h_{n s i, j}^{0}\right] \\
h_{s a t i, j}^{n}-h_{s a t i, j}^{0}=p_{i, j} \Delta t \\
(c h)_{i, j}^{n}-(c h)_{i, j}^{0}=K_{i i, j} P e_{i, j} \Delta t
\end{gathered}
$$

where the superindex 0 indicates the variable evaluated at time $t$ and $n$ the variable evaluated after the vertical contributions during one time step.

Equations (3.1) to (3.4) govern the interaction between levels in a decoupled way.

When the water table reaches the soil bed elevation at any cell, all the in-going groundwater and subsurface water in that cell are immediately transmitted to the surface level. In addition, the non-saturated level disappears in that cell and all the terrain depth becomes saturated $h_{s a t}=z_{b}-z_{h}$.

\section{Surface flow}


The overland equation of the EKW model for the homogeneous case is:

$$
\frac{\partial h}{\partial t}+\nabla \cdot\left(\frac{h^{5 / 3}}{n \sqrt{|\mathbf{S}|}} \mathbf{S}\right)=\frac{\partial h}{\partial t}+\nabla \cdot \boldsymbol{q}=0
$$

Taking into account that there is a marked advection character in the EKW and DW models, a first order in space and time explicit upwind scheme has been chosen for the discretization as it has been demonstrated that this scheme is TVD (monotone and nonoscillatory) (Burguete and García Navarro, 2001). Explicit models present advantages when compared with implicit models in many gradually varying problems (Wasantha Lal, 1998, appendix A).

The upwind scheme is based on approximating the spatial derivatives using the direction and sign of the advection velocity. According to this idea, the flux difference is split in in-going and out-going parts at each cell edge. Only the in-going contributions are necessary to update a cell value variable. Denoting the edges of cell $(i, j)$ as $(i+1 / 2, j),(i-$ $1 / 2, j),(i, j+1 / 2)$ and $(i, j-1 / 2)$ the discretization of (3.5) leads to the following scheme for the calculation of the new water depth at time $t+\Delta t$ :

$$
h_{i, j}^{n+1}=h_{i, j}^{n}-\frac{\Delta t}{\Delta x \Delta y}\left[\left(\delta q_{x}^{n}\right)_{i-1 / 2, j}^{+} \Delta x+\left(\delta q_{x}^{n}\right)_{i+1 / 2, j}^{-} \Delta x+\left(\delta q_{y}^{n}\right)_{i, j-1 / 2}^{+} \Delta y+\left(\delta q_{y}^{n}\right)_{i, j+1 / 2}^{-} \Delta y\right]
$$

with $\Delta x, \Delta y$ the length of the edges and 


$$
\begin{aligned}
& \left.\left(\delta q_{x}^{n}\right)_{i+1 / 2, j}^{-}=\frac{1-\operatorname{sign}\left[\left(\lambda_{x}^{n}\right)_{i+1 / 2, j}\right]}{2}\right]\left[\left(q_{x}^{l}\right)_{i+1, j}^{n}-\left(q_{x}^{l}\right)_{i, j}^{n}\right] \\
& \left.\left(\delta q_{x}^{n}\right)_{i+1 / 2, j}^{+}=\frac{1+\operatorname{sign}\left[\left(\lambda_{x}^{n}\right)_{i+1 / 2, j}\right]}{2}\right]\left[\left(q_{x}^{r}\right)_{i+1, j}^{n}-\left(q_{x}^{r}\right)_{i, j}^{n}\right] \\
& \left.\left(\delta q_{y}^{n}\right)_{i, j+1 / 2}^{-}=\frac{1-\operatorname{sign}\left[\left(\lambda_{y}^{n}\right)_{i, j+1 / 2}\right]}{2}\right]\left[\left(q_{y}^{t}\right)_{i, j+1}^{n}-\left(q_{y}^{t}\right)_{i, j}^{n}\right] \\
& \left.\left(\delta q_{y}^{n}\right)_{i, j+1 / 2}^{+}=\frac{1+\operatorname{sign}\left[\left(\lambda_{y}^{n}\right)_{i, j+1 / 2}\right]}{2}\right]\left[\left(q_{y}^{b}\right)_{i, j+1}^{n}-\left(q_{y}^{b}\right)_{i, j}^{n}\right]
\end{aligned}
$$

where additional discharges are defined at the cell edges for conservation purposes (Fig.4):

$$
\begin{aligned}
& \left\{\begin{array}{l}
\left(q_{x}^{l}\right)_{i, j}=\frac{h_{i, j}^{5 / 3}\left(S_{x}\right)_{i-1 / 2, j}}{n_{i, j} \mid \mathbf{S}_{i-1 / 2, j}} \\
\left(q_{x}^{r}\right)_{i, j}=\frac{h_{i, j}^{5 / 3}\left(S_{x}\right)_{i+1 / 2, j}}{n_{i, j}|\mathbf{S}|_{i+1 / 2, j}}
\end{array}\right\} \quad \text { if } \quad \operatorname{sign}\left(S_{x i-1 / 2, j}\right)=\operatorname{sign}\left(S_{x_{i+1 / 2, j}}\right) \text { or } \quad S_{x_{i+1 / 2, j}}>0 \\
& \left.\begin{array}{l}
\left(\begin{array}{l}
l \\
q_{x}
\end{array}\right)_{i, j}=0 \\
\left(q_{x}^{r}\right)_{i, j}=0
\end{array}\right\} \quad \text { if } \quad \operatorname{sign}\left(S_{x_{i-1 / 2, j}}\right) \neq \operatorname{sign}\left(S_{x_{i+1 / 2, j}}\right) \text { and } S_{x_{i+1 / 2, j}}<0 \\
& \left\{\begin{array}{c}
\left(q_{y}^{b}\right)_{i, j}=\frac{h_{i, j}^{5 / 3}\left(S_{y}\right)_{i, j-1 / 2}}{n_{i, j}|\mathbf{S}|_{i, j-1 / 2}} \\
\left(q_{y}^{t}\right)_{i, j}=\frac{h_{i, j}^{5 / 3}\left(S_{y}\right)_{i, j+1 / 2}}{n_{i, j} \sqrt{\left.\mathbf{S}\right|_{i, j+1 / 2}}}
\end{array}\right\} \quad \text { if } \operatorname{sign}\left(S_{y_{i, j-1 / 2}}\right)=\operatorname{sign}\left(S_{y_{i, j+1 / 2}}\right) \text { or } \quad S_{y_{i, j+1 / 2}}>0
\end{aligned}
$$

$\lambda$ is the advection velocity defined as:

$$
\lambda=\left(\lambda_{x}, \lambda_{y}\right)=\left(\frac{\partial q_{x}}{\partial h}, \frac{\partial q_{y}}{\partial h}\right) \approx\left(\frac{5 h^{2 / 3} S_{x}}{3 n \sqrt{|\boldsymbol{S}|}}, \frac{5 h^{2 / 3} S_{y}}{3 n \sqrt{|\boldsymbol{S}|}}\right)
$$

Equation (3.9) is exact in the particular case of the KW model.

The slopes are evaluated at cell edges as: 


$$
\begin{aligned}
& \left(S_{x}\right)_{i+1 / 2, j}=-\frac{z_{b i+1, j}-z_{b i, j}+m\left(h_{i+1, j}-h_{i, j}\right)}{\Delta \mathrm{x}}, \quad\left(S_{y}\right)_{i, j+1 / 2}=-\frac{z_{b i, j+1}-z_{b i, j}+m\left(h_{i, j+1}-h_{i, j}\right)}{\Delta \mathrm{y}} \\
& (\mathbf{S})_{i+1 / 2, j}=\left(S_{x}, S_{y}\right)_{i+1 / 2, j}=\left(\left(S_{x}\right)_{i+1 / 2, j}, \frac{\left(S_{y}\right)_{i, j+1 / 2}+\left(S_{y}\right)_{i, j-1 / 2}+\left(S_{y}\right)_{i+1, j+1 / 2}+\left(S_{y}\right)_{i+1, j-1 / 2}}{4}\right) \\
& (\mathbf{S})_{i, j+1 / 2}=\left(S_{x}, S_{y}\right)_{i, j+1 / 2}=\left(\frac{\left(S_{x}\right)_{i+1 / 2, j}+\left(S_{x}\right)_{i-1 / 2, j}+\left(S_{x}\right)_{i+1 / 2, j+1}+\left(S_{x}\right)_{i-1 / 2, j+1}}{4},\left(S_{y}\right)_{i, j+1 / 2}\right)
\end{aligned}
$$

Figure 4. Splitting of the unit discharge in two components in cell $(\mathrm{i}, \mathrm{j})$.

When $m=0$ equations (3.6) to (3.10) represent a discretization of the KW model. When $m=1$, equations (3.6) to (3.10) represent a discretization of the DW model and, and for the EKW model, the value of $m$ is proposed to be:

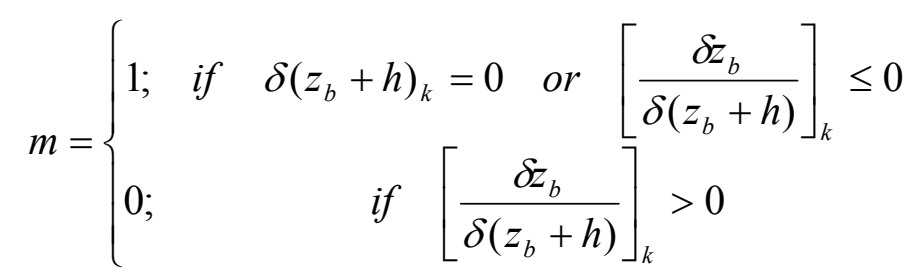

where sub-index $k$ indicates slope evaluation at a grid edge.

The Courant-Friedrich-Lewy (CFL) condition is standard for the stability control of explicit schemes. When applied to (3.6), in cases where $\mathbf{q}=\mathbf{q}(h)$, the CFL condition leads to the following limit on the time step (Murillo et al., 2006): 


$$
\Delta t_{i, j}=C F L \frac{\Delta x}{2 \max \left(\left|\lambda_{x_{i+1 / 2, j}}\right|,\left|\lambda_{y_{i, j+1 / 2}}\right|\right)}
$$

with $C F L \leq 1$. For stable solutions, $\Delta t=\min \left\{\Delta t_{i, j}\right\}$. As $\mathbf{q}=\mathbf{q}(h, \mathbf{S}, n)$ in general, (3.12) is not enough to guarantee the numerical stability of the solution. The new condition proposed here is:

$$
\Delta t_{i, j}=C F L \frac{\Delta x}{\left.2 \max \left[\left|\left(\lambda_{x_{i+1 / 2, j}^{*}}^{*}\right)^{+}\right|,\left|\left(\lambda_{x_{i+1 / 2, j}^{*}}^{*}\right)^{-}\right|,\left(\lambda_{y_{i, j+1 / 2}^{*}}^{*}\right)^{+}|,|\left(\lambda_{y_{i, j+1 / 2}^{*}}^{*}\right)^{-}\right]\right]}
$$

where

$$
\begin{aligned}
& \left.\left(\lambda_{x_{i+1 / 2, j}}^{*}\right)^{+}=\frac{1+\operatorname{sign}\left[\left(\lambda_{x}^{n}\right)_{i+1 / 2, j}\right]}{2} \frac{\left(q_{x}^{l}\right)_{i+1, j}^{n}-\left(q_{x}^{l}\right)_{i, j}^{n}}{h_{i+1, j}-h_{i, j}}\right)
\end{aligned}
$$

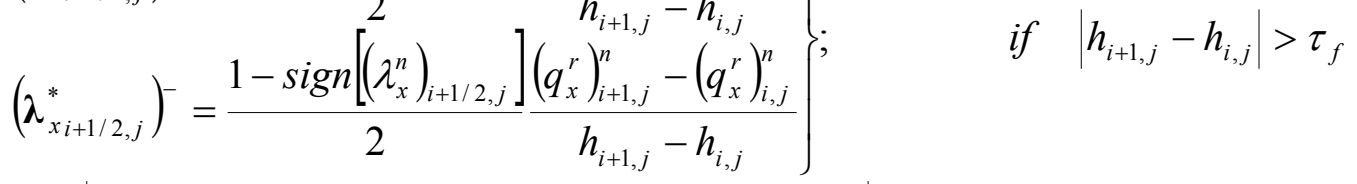

$$
\begin{aligned}
& \left(\lambda_{x i+1 / 2, j}^{*}\right)^{ \pm}=\left|\frac{h^{2 / 3} S_{x}}{n \sqrt{\mid \mathbf{S}}}\left[\frac{25}{9}+\left(\frac{m \pi h|\mathbf{S}|}{4\left(S_{x}\right)^{2} \Delta x}\right)^{2}\right]\left[\frac{5}{3}+\frac{m \pi h|\mathbf{S}|}{4\left(S_{x}\right)^{2} \Delta x}\right]^{-1}\right|_{i+1 / 2, j} \quad ; \quad \text { if } \quad\left|h_{i+1, j}-h_{i, j}\right| \leq \tau_{f} \\
& \left.\left(\lambda_{y_{i, j+1 / 2}}^{*}\right)^{+}=\frac{1+\operatorname{sign}\left[\left(\lambda_{y}^{n}\right)_{i, j+1 / 2}\right]}{2} \frac{\left(q_{y}^{t}\right)_{i, j+1}^{n}-\left(q_{y}^{t}\right)_{i, j}^{n}}{h_{i, j+1}-h_{i, j}}\right) \\
& \left.\left(\lambda_{y_{i, j+1 / 2}^{*}}^{*}\right)^{-}=\frac{1-\operatorname{sign}\left[\left(\lambda_{y}^{n}\right)_{i, j+1 / 2}\right]}{2} \frac{\left(q_{y}^{b}\right)_{i, j+1}^{n}-\left(q_{y}^{b}\right)_{i, j}^{n}}{h_{i, j+1}-h_{i, j}}\right\} \\
& \text { if } \quad\left|h_{i, j+1}-h_{i, j}\right|>\tau_{f} \\
& \left(\lambda_{y_{i, j+1 / 2}^{*}}^{*}\right)^{ \pm}=\left|\frac{h^{2 / 3} S_{y}}{n \sqrt{\mid \mathbf{S}}}\left[\frac{25}{9}+\left(\frac{m \pi h|\mathbf{S}|}{4\left(S_{y}\right)^{2} \Delta y}\right)^{2}\right]\left[\frac{5}{3}+\frac{m \pi h|\mathbf{S}|}{4\left(S_{y}\right)^{2} \Delta y}\right]^{-1}\right|_{i, j+1 / 2} \quad ; \quad \text { if } \quad\left|h_{i, j+1}-h_{i, j}\right| \leq \tau_{f}
\end{aligned}
$$

where $\tau_{f}$ is a tolerance parameter to avoid division by zero.

\section{Entropy correction}


Lax (1973) introduced the concept of entropy correction as a condition that the numerical schemes must satisfy for the solution to be physically acceptable near sonic points in the context of gas dynamics. In the case of the upwind scheme applied to EKW or DW models that effect takes place in the cells where the slope changes from negative to positive (in the local maxima). For instance, when $\lambda_{x i+1 / 2, j}>0$ and $\lambda_{x i-1 / 2, j}<0$ there is no information entering cell $i, j$ in direction $x$. Thus, the value of the variable $h_{i, j}$ does not vary by effect of the fluxes propagating in that direction. It is analogous in direction $y$ (figure 5).

Figure 5. Local maximum at cell $(\mathrm{i}, \mathrm{j})$, lack of information schematic representation.

In analogy to what is done in the case of the complete Saint Venant models (Burguete and García Navarro, 2001) an entropy correction is introduced to solve this effect as follows:

$$
\begin{aligned}
& h_{i, j}^{n+1}=h_{i, j}^{n}-\frac{\Delta t}{\Delta x \Delta y}\left[\left(\delta q_{x}^{n}\right)_{i-1 / 2, j}^{+} \Delta x+\left(\delta q_{x}^{n}\right)_{i+1 / 2, j}^{-} \Delta x+\left(\delta q_{y}^{n}\right)_{i, j-1 / 2}^{+} \Delta y+\left(\delta q_{y}^{n}\right)_{i, j+1 / 2}^{-} \Delta y\right] \\
& -\frac{\Delta t}{\Delta x \Delta y}\left[\mu_{x}\left(\left|q^{r}\right|+\left|q^{l}\right|\right) \Delta x+\mu_{y}\left(\left|q^{t}\right|+\left|q^{b}\right|\right) \Delta y\right]_{i, j}^{n}
\end{aligned}
$$

where

$$
\begin{aligned}
& \mu_{x i, j}=\left\{\begin{array}{lll}
1 ; & \text { if } & \operatorname{sign}\left(S_{x i-1 / 2, j}\right) \neq \operatorname{sign}\left(S_{x_{i+1 / 2, j}}\right) \\
0 ; & \text { if } & \operatorname{sign}\left(S_{x i-1 / 2, j}\right)=\operatorname{sign}\left(S_{x i+1 / 2, j}\right) \\
\text { ord } & S_{x i+1 / 2, j}>0 \\
S_{x i+1 / 2, j} & <0
\end{array}\right.
\end{aligned}
$$

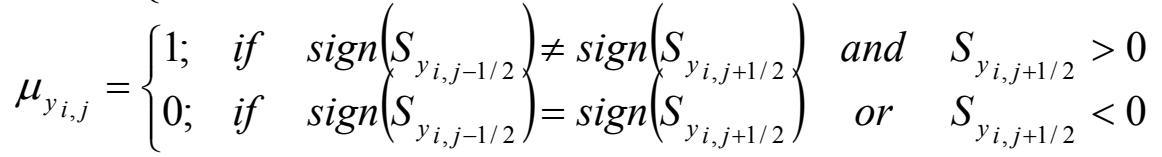

\section{$\underline{\text { Boundary conditions }}$}


Total input and output discharges $\left(Q_{i}\right.$ and $\left.Q_{o}\right)$ are the sum of the contributions of all the involved boundary edges:

$$
Q_{i}=\sum_{m=1}^{N I C} \sum_{k=1}^{N I E} Q_{k m} \Delta x \quad \text { and } \quad Q_{o}=\sum_{m=1}^{N O C} \sum_{k=1}^{N O E} Q_{k m} \Delta x
$$

where NIC, NOC are the number of input or output cells in the mesh, NIE, NOE are the number of input or output edges of boundary cell $m$. The use of (3.17) is performed using $Q_{k m}=q_{x m}^{r}$ for a right boundary edge, $Q_{k m}=-q_{x m}^{l}$ for a left boundary edge, $Q_{k m}=q_{y_{m}}^{b}$ for a bottom boundary edge or $Q_{y_{m}}=-q_{y_{m}}^{t}$ for a top boundary edge (see 3.8).

In the case of closed contours (solid walls) $\left(\delta q_{x}\right)_{k}^{ \pm}$and $\left(\delta q_{y}\right)_{k}^{ \pm}$must be defined. Depending on whether the closed contour is at the left, right, top or bottom side of the cell, the correct definitions would be $\left(\delta q_{x}\right)_{i+1 / 2, j}^{-}=q_{x i, j}^{r},\left(\delta q_{x}\right)_{i-1 / 2, j}^{+}=-q_{x i, j}^{l},\left(\delta q_{y}\right)_{i, j+1 / 2}^{-}=q_{u i, j}^{b}$ or $\left(\delta q_{y}\right)_{i, j-1 / 2}^{+}=-q_{u i, j}^{t}$ respectively.

All imposed boundary condition must be formulated in terms of the conserved variable $h(t)$ and the relation between water depth and discharge is provided by (C.10).

\section{Sediment transport}

The sediment transport equation is discretized as the overland flow except for the source term $E_{r}$ that is approximated in a centred way, 


$$
\begin{aligned}
& (c h)_{i, j}^{n+1}=(c h)_{i, j}^{n}-\frac{\Delta t}{\Delta x \Delta y}\left[\left(\delta(c q)_{x}^{n}\right)_{i-1 / 2, j}^{+} \Delta x+\left(\delta(c q)_{x}^{n}\right)_{i+1 / 2, j}^{-} \Delta x+\left(\delta(c q)_{y}^{n}\right)_{i, j-1 / 2}^{+} \Delta y\right. \\
& \left.+\left(\delta(c q)_{y}^{n}\right)_{i, j+1 / 2}^{-} \Delta y\right]-\frac{\Delta t}{\Delta x \Delta y}\left[\mu_{x}\left(\left|c q^{r}\right|+\left|c q^{l}\right|\right) \Delta x+\mu_{y}\left(\left|c q^{t}\right|+\left|c q^{b}\right|\right) \Delta y\right]_{i, j}^{n} \\
& +k_{r i, j}\left(\frac{n_{i, j} B_{i, j}}{\sqrt{S_{i, j}}}-c_{i, j}\right)\left|\boldsymbol{q}_{i, j}\right| \Delta t
\end{aligned}
$$

where $S_{i j}$ is the modulus of the slope vector evaluated at the cell centre in the way:

$$
(\mathbf{S})_{i, j}=\left(S_{x}, S_{y}\right)_{i, j}=\left(\frac{S_{x i+1 / 2, j}+S_{x i-1 / 2, j}}{2}, \frac{S_{y_{i, j+1 / 2}}+S_{y_{i, j-1 / 2}}}{2}\right)
$$

The stability condition for the sediment transport equation is:

$$
\Delta t_{i}=C F L \frac{\Delta x}{2 \max \left[\left|\left(\lambda_{x_{i+1 / 2, j}}^{*}\right)^{+}\right|,\left|\left(\lambda_{x_{i+1 / 2, j}}^{*}\right)^{-}\right|,\left|\left(\lambda_{y_{i, j+1 / 2}}^{*}\right)^{+}\right|,\left|\left(\lambda_{y_{i, j+1 / 2}}^{*}\right)^{-}\right|\right]}
$$

with $C F L \leq 1$ where the definition of the approximate advection velocities is as in (3.14) changing $h$ by $(c h)$ and $q$ by $(c q)$.

Boundary conditions in the case of the sediment transport model are imposed analogously to what was done before. In this case the conserved variable is (ch) and the total discharges and unit discharges are $(c \boldsymbol{Q})$ and $(c \boldsymbol{q})$.

\section{Groundwater and unsaturated zones}


Due to the different character of the equations, central differences have been used for the sub-surface model. For the saturated zone:

$$
\begin{aligned}
& h_{\text {sat } i, j}^{n+1}=h_{\text {sat } i, j}^{n}-\frac{\Delta t}{(\Delta x)^{2}}\left\{-k_{S 0 i+1 / 2, j} h_{s a t i+1 / 2, j}^{n}\left[\left(z_{h}+h_{s a t}\right)_{i+1, j}^{n}-\left(z_{h}+h_{s a t}\right)_{i, j}^{n}\right]\right. \\
& +k_{S 0 i-1 / 2, j} h_{s a t i-1 / 2, j}^{n}\left[\left(z_{h}+h_{s a t}\right)_{i, j}^{n}-\left(z_{h}+h_{s a t}\right)_{i-1, j}^{n}\right] \\
& -k_{S 0 i, j+1 / 2} h_{s a t i, j+1 / 2}^{n}\left[\left(z_{h}+h_{s a t}\right)_{i, j+1}^{n}-\left(z_{h}+h_{s a t}\right)_{i, j}^{n}\right] \\
& \left.+k_{S 0 i, j-1 / 2} h_{s a t i, j-1 / 2}^{n}\left[\left(z_{h}+h_{s a t}\right)_{i, j}^{n}-\left(z_{h}+h_{s a t}\right)_{i, j-1}^{n}\right]\right\}
\end{aligned}
$$

For the unsaturated level:

$$
\begin{aligned}
& h_{n s i, j}^{n+1}=h_{n s i, j}^{n}-\frac{\Delta t}{(\Delta x)^{2}}\left\{-k_{S_{i+1 / 2, j}} h_{n s i+1 / 2, j}^{n}\left[\left(z+h_{n s}\right)_{i+1, j}^{n}-\left(z+h_{n s}\right)_{i, j}^{n}\right]\right. \\
& +k_{S_{i-1 / 2, j}} h_{n s i-1 / 2, j}^{n}\left[\left(z+h_{n s}\right)_{i, j}^{n}-\left(z+h_{n s}\right)_{i-1, j}^{n}\right] \\
& -k_{S_{i, j+1 / 2}} h_{n s i, j+1 / 2}^{n}\left[\left(z+h_{n s}\right)_{i, j+1}^{n}-\left(z+h_{n s}\right)_{i, j}^{n}\right] \\
& \left.+k_{S i, j-1 / 2} h_{n s i, j-1 / 2}^{n}\left[\left(z+h_{n s}\right)_{i, j}^{n}-\left(z+h_{n s}\right)_{i, j-1}^{n}\right]\right\}
\end{aligned}
$$

In both cases the appropriate time step to avoid instabilities is:

$$
\Delta t \leq \frac{(\Delta x)^{2}}{4 k_{i, j} h_{s i, j}}
$$

being $h_{s}=h_{s a t}$ and $k=k_{S 0}$ for the groundwater flow and $h_{s}=h_{n s}$ and $k=k_{S}$ for the unsaturated flow. In the case of subsurface flows the restriction over time step is imposed by (3.23) but, due to the small values of hydraulic conductivity, is not usually the most restrictive. So the water surface stability condition is usually dominant. 


\section{$\underline{\text { Boundary conditions }}$}

In closed contour condition the edge hydraulic slope (first derivative) is set to zero at the corresponding edge. Otherwise the second derivative is set to zero at the edge in the same cell. As in the case of the surface flow, all boundary conditions must be formulated in terms of the conserved variables $h_{\text {sat }}(t)$ and $h_{n s}(t)$.

\section{Mass error}

As the proposed scheme is conservative, the total water volume in the domain at every time step $V^{n+1}\left(V^{n+1}=\sum_{i=1}^{N_{x}} \sum_{i=1}^{N_{y}}\left(h_{i, j}^{n+1}+h_{n s, i, j}^{n+1}+h_{s a t, i, j}^{n+1}\right) \delta x \delta y\right)$ must be equal to that existing in the previous time step $V^{n}\left(V^{n}=\sum_{i=1}^{N_{x}} \sum_{i=1}^{N_{y}}\left(h_{i, j}^{n}+h_{n s, i, j}^{n}+h_{s a t, i, j}^{n}+P e \Delta t\right) \delta x \delta y\right)$ plus or minus the mass introduced or subtracted through the boundaries. However, as it is a computational model, truncation may introduce some errors. Then, to prove the mass conservation property, the absolute percentage mass error is calculated as:

$$
\varepsilon(\%)=\left|\frac{V^{n+1}-V^{n}-Q_{\text {inlet }}^{n} \Delta t+Q_{\text {outlet }}^{n} \Delta t}{V^{n}+Q_{\text {inlet }}^{n} \Delta t-Q_{\text {outlet }}^{n} \Delta t}\right| \cdot 100
$$

The same can be done with the solid mass:

$$
\varepsilon_{s}=\left|\frac{\sum_{i=1}^{N_{x}} \sum_{i=1}^{N_{y}}(c h)_{i, j}^{n+1} \delta x \delta y-\sum_{i=1}^{N_{x}} \sum_{i=1}^{N_{y}}\left[(c h)_{i, j}^{n}+A_{i, j} \Delta t\right] \delta x \delta y-(c Q)_{\text {inlet }}^{n} \Delta t-(c Q)_{\text {outlet }}^{n} \Delta t}{\sum_{i=1}^{N_{x}} \sum_{i=1}^{N_{y}}\left[(c h)_{i, j}^{n}+A_{i, j} \Delta t\right] \delta x \delta y-(c Q)_{\text {inlet }}^{n} \Delta t+(c Q)_{\text {outlet }}^{n} \Delta t}\right| \cdot 100
$$


where:

$$
A_{i, j}=k_{r i, j}\left(\frac{n_{i, j} B_{i, j}}{\sqrt{S_{i, j}}}-c_{i, j}\right)\left|\boldsymbol{q}_{i, j}\right|+K_{i i, j} P e_{i, j}
$$

\section{$\underline{\text { Conclusions }}$}

A 2D distributed numerical model has been proposed for the simulation of rainfallrunoff events. The motivation behind this development is the best compromise between physical basis and computational efficiency. For the overland flow component, a new general formulation that includes both the KW and the DW models has been presented. The new formulation is also able to represent the Extended Kinematic Wave (EKW) model developed to enable the application of the KW in processes with local minima or zero bed slope zones. The three overland flow models can be supplied with a 2D extension of the Hillslope Erosion Model (HEM) to simulate sediment transport phenomena. The overland flow model is completed with simple but physically based laws to simulate the evapotranspiration, the infiltration, the sub-superficial and groundwater flows and the exchanges between subsuperficial and groundwater flows and the bed and the ground. Although more complex laws could be used to simulate these processes, the lack of information available in real basins makes that effort not efficient.

Our model pays special attention to the physical meaning of the overland flow model, written in the form of a conservation law, and using an appropriate discretization scheme. Therefore, our work is devoted to get a deep understanding of the mass conservation and numerical stability constraints. The surface flow and the sediment transport discretization have been done via a first order upwind explicit method with entropy correction to ensure mass (volume) conservation in the regions with local maxima in the bed/surface slopes 
driving the flow. The upwind scheme is based on approximating the spatial derivatives using the direction and sign of the advection velocity. According to this idea, the flux difference is split between in-going and out-going parts at each cell edge. The explicit time integration has proved to be the best option as the implicit version is less accurate and inefficient (appendix A).

The classical Fourier stability analysis of the explicit upwind method applied to the overland flow EKW equation has been presented. It shows that, when the model reduces to the KW formulation, an exact stability condition can be found (CFL condition). The DW and EKW models are more restrictive and the CFL condition is not enough to guarantee these methods' stability. The analysis of the stability limit shows that, in general, the model will be more efficient for coarser meshes. This happens not only for the traditional reason that less grid cells lead to less computational cost, but also because the discrete surface slope approaches the bed slope, hence convection gets a predominant role in the discrete representation. A dynamically variable time step has been set to guarantee stability of the complete hydrologic-hydraulic model as the transient flow develops. This time step requires the definition of a tolerance factor $\tau_{f}$.

Finally, it may be concluded that, despite their theoretical simplicity, the DW and EKW models present important shortcomings for their practical application in twodimensional overland flow simulation.

The validation of the model and the application to realistic cases is presented in a companion paper.

\section{$\underline{\text { Appendix A }}$}

\section{Implicit model based on the Thomas algorithm}


For simplicity, the homogeneous equation of the 1D DW model is considered.

$\frac{\partial h}{\partial t}+\frac{\partial q(x, h)}{\partial x}=\frac{\partial h}{\partial t}+\frac{\partial[v(x, h) h(x)]}{\partial x}=0$ where $\quad v=\lambda=\frac{h^{2 / 3} \sqrt{S_{d}}}{n}=\frac{h^{2 / 3} \sqrt{-\frac{\partial(z+h)}{\partial x}}}{n}$

Then, the implicit discretization leads to:

$$
\frac{\Delta h_{i}}{\Delta t}+\frac{1}{\Delta x}\left(\delta q_{i-1 / 2}^{+}+\delta q_{i+1 / 2}^{-}\right)^{n+\theta}=0
$$

where the + and - signs are defined as in (3.7) and where $0<\theta \leq 1$, $\delta q^{n+\theta}=\theta \delta q^{n+1}+(1-\theta) \delta q^{n}$, being:

$$
\delta q_{i+1 / 2}^{n}=v_{i+1 / 2}^{n} \delta h_{i+1 / 2}^{n}+h_{i+1 / 2}^{n} \delta v_{i+1 / 2}^{n} \text { and } \delta q_{i+1 / 2}^{n+1}=v_{i+1 / 2}^{n} \delta h_{i+1 / 2}^{n+1}+h_{i+1 / 2}^{n} \delta v_{i+1 / 2}^{n+* *}
$$

There are several ways of calculating $\left(\bar{v}_{i+1 / 2}^{ \pm}\right)^{n+* *}$. On the one hand, $\left(\bar{v}_{i+1 / 2}^{ \pm}\right)^{n+* *}=0$ can be assumed. On the other hand, assuming $\left(\bar{v}_{i+1 / 2}^{ \pm}\right)^{n+* *}=\left(\bar{v}_{i+1 / 2}^{ \pm}\right)^{n}$ at a first stage, an iterative method can be used, using the new value of the conserved variable to make a better estimation of $\left(\bar{v}_{i+1 / 2}^{ \pm}\right)^{n+* *}=\left(\bar{v}_{i+1 / 2}^{ \pm}\right)^{n}$

It can be proved that, in case of using $\theta=1$, the stability is guaranteed for every time step. Using $\theta=1$ :

$$
A_{i}^{n} \Delta h_{i-1}^{n}+B_{i}^{n} \Delta h_{i}^{n}+C_{i}^{n} \Delta h_{i+1}^{n}+=D_{i}^{n}
$$


where:

$$
\begin{gathered}
A_{i}^{n}=-\theta\left(v_{i-1 / 2}^{n}\right)^{+} \\
B_{i}^{n}=\theta\left(v_{i-1 / 2}^{n}\right)^{+}-\theta\left(v_{i+1 / 2}^{n}\right)^{-}+\frac{\Delta x}{\Delta t} \\
C_{i}^{n}=\theta\left(v_{i+1 / 2}^{n}\right)^{-} \\
D_{i}^{n}=-\left(v_{i-1 / 2}^{n}\right)^{+} \delta h_{i-1 / 2}^{n}-\left(v_{i+1 / 2}^{n}\right)^{-} \delta h_{i+1 / 2}^{n} \\
-\theta h_{i-1 / 2}^{n} \frac{1+\operatorname{sign}\left(v_{i-1 / 2}^{n+*}\right)}{2}\left(v_{i}^{n+* *}-v_{i-1}^{n+* *}\right)-(1-\theta) h_{i-1 / 2}^{n} \frac{1+\operatorname{sign}\left(v_{i-1 / 2}^{n}\right)}{2}\left(v_{i}^{n}-v_{i-1}^{n}\right) \\
-\theta h_{i+1 / 2}^{n} \frac{1-\operatorname{sign}\left(v_{i+1 / 2}^{n+*}\right)}{2}\left(v_{i+1}^{n+* *}-v_{i}^{n+* *}\right)-(1-\theta) h_{i-1 / 2}^{n} \frac{1-\operatorname{sign}\left(v_{i+1 / 2}^{n}\right)}{2}\left(v_{i+1}^{n}-v_{i}^{n}\right)
\end{gathered}
$$

To apply the Thomas algorithm we assume:

$$
\Delta h_{i+1}=\gamma_{i+1}-\alpha_{i+1} \Delta h_{i}
$$

where $\alpha$ and $\gamma$ are two coefficients. Replacing (A.6) in (A.5):

$$
\gamma_{i}=\frac{D_{i}^{n}-C_{i}^{n} \gamma_{i+1}}{B_{i}^{n}-\alpha_{i+1} C_{i}^{n}}, \quad \alpha_{i}=\frac{A_{i}^{n}}{B_{i}^{n}-\alpha_{i+1} C_{i}^{n}}
$$

Then, knowing the values of the coefficients $\alpha$ and $\gamma$ at the output boundary their values at the whole domain can be calculated and knowing $\Delta h_{0}, \Delta h_{i}$ can be computed at the whole domain through A.6.

We define the $C F L$ number as: 


$$
C F L=\frac{\Delta t}{\frac{\Delta x}{3} \frac{h_{0}^{2 / 3} \sqrt{S_{0}}}{n}}
$$

Although the model is stable for any value of the $C F L$ number and appropriate to simulate phenomena near steady state with great time steps, it is not accurate to simulate transient phenomena when using $C F L>1$.

To illustrate this behaviour, the case of the advance of a wave over an initially dry steep plane is presented. The plane is $100 \mathrm{~m}$ long, $10 \mathrm{~m}$ wide and the slope is $1 \%$. The Manning roughness coefficient is $0.05 \mathrm{~s} / \mathrm{m}^{1 / 3}$. The upstream boundary condition was set at $Q(t)=$ $6.3 \mathrm{~m}^{3} / \mathrm{s}$ calculated with the formula (3.14) using $S_{x}=S_{0 x}$. Downstream boundary conditions $\gamma_{N}=0$ and $\alpha_{N}=-1$ were imposed and $\left(\bar{v}_{i+1 / 2}^{ \pm}\right)^{n+* *}=0$ is assumed. Figure 6 shows the advance profile at $t=50 \mathrm{~s}$ when the $\mathrm{KW}$ model is used $(m=0)$ and different CFL numbers are imposed.

Figure 6. Wave advance profile at $t=50$ s using different CFL numbers.

Figure 6 shows that, as the $C F L$ increases, the simulated solution differs more from the exact solution. Then, the implicit scheme is not reliable to simulate transient flows with sharp advance profiles. These kinds of limitations are common to other implicit schemes used by other authors (Wasantha Lal, 1998; VanderKwaak, 1999; Luo, 2007). The extension of the implicit scheme to 2D flows taking into account the entropy correction on rectangular grids is straightforward. 


\section{$\underline{\text { Appendix B }}$}

\section{Explicit upwind scheme for surface flow stability analysis}

The explicit EKW model stability analysis is carried out via a classical Fourier analysis. For simplicity, a pure 1D phenomenon is studied. A small sinusoidal perturbation is introduced over a non-perturbed state in the way $h=h_{0}+h_{1} e^{i k x}$ :

As a first approximation, the bed slope is assumed to be uniform and the free surface slope to be positive. In these conditions equation (3.6) is reduced to:

$$
h_{i, j}^{n+1}=h_{i, j}^{n}-\frac{\Delta t}{\Delta x}\left(\delta q_{x}^{n}\right)_{i-1 / 2, j}^{+}=h_{i, j}^{n}-\frac{\Delta t}{\Delta x}\left[\left(q_{x}^{r}\right)_{i, j}^{n}-\left(q_{x}^{r}\right)_{i-1, j}^{n}\right]
$$

and

$$
q_{x}^{r}=\frac{h^{5 / 3} \sqrt{S_{0}-m \frac{\partial h}{\partial x}}}{n}
$$

A Taylor expansion up to first order in $h_{l}$ leads to:

$$
\left(q^{r}\right)_{i}^{n}=\frac{h_{0}^{5 / 3} \sqrt{S_{0}}}{n}\left(1+\frac{5}{3} \frac{h_{1}}{h_{0}} e^{i k x}-\frac{m i k h_{1} e^{i k x}}{2 S_{0}}\right)
$$

Inserting (B.3) in (B.1):

$$
h_{i}^{n+1}=h_{0}+h_{1} e^{i k x}\left[1-\frac{\Delta t}{\Delta x} \frac{h_{0}^{2 / 3} \sqrt{S_{0}}}{n}\left(1-e^{-i k \Delta x}\right)\left(\frac{5}{3}-\frac{m i k h_{0}}{2 S_{0}}\right)\right]
$$


The stability of this equation comes from the no amplification condition:

$$
\Delta t \leq \frac{\Delta x\left[\frac{5}{3}+\frac{m k h_{0}}{2 S_{0}} \frac{\sin (k \Delta x)}{1-\cos (k \Delta x)}\right]}{\frac{h_{0}^{2 / 3} \sqrt{S_{0}}}{n}\left[\frac{25}{9}+\left(\frac{m k h_{0}}{2 S_{0}}\right)^{2}\right]}
$$

At the discrete level the shortest sinusoidal wave is that with wavelength $\lambda=4 \Delta x$, or $k \Delta x \in(0, \pi / 2]$. Thus, the most restrictive condition imposed by equation (B.5) corresponds to $k=\pi / 2$ :

$$
\Delta t \leq \frac{\Delta x\left[\frac{5}{3}+\frac{m \pi h_{0}}{4 S_{0} \Delta x}\right]}{\frac{h_{0}^{2 / 3} \sqrt{S_{0}}}{n}\left[\frac{25}{9}+\left(\frac{m \pi h_{0}}{4 S_{0} \Delta x}\right)^{2}\right]}
$$

This can be split in two factors:

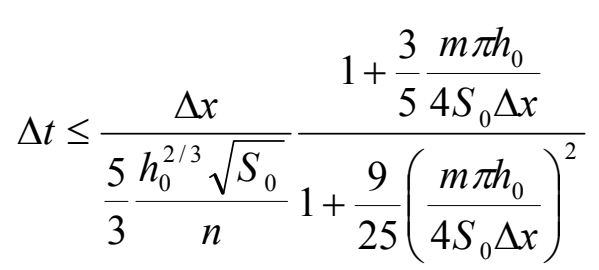

The first factor in (B.5) is the KW stability limit governed by the kinematic wave advection velocity (3.9) and is here referred to as the CFL condition.

Under the present assumptions, the condition proposed in (3.13) for $h_{i} \neq h_{i+1}$ 
coincides with (B.6). For that reason, (B.6) can be said to provide the alternative expression for the discrete time step condition (3.13) when $h_{i}=h_{i+1}$.

Equation (B.6) also shows that, for given $\left(h_{0}, S_{0}, n\right)$ values, when $\pi h_{0} /\left(4 S_{0} \Delta x\right)>1$, the DW $(m=1)$ stability condition is more restrictive. This was expected due to the diffusive character of the original DW equation. In the limit of $\pi h_{0} /\left(4 S_{0} \Delta x\right)>>1$ the stability limit is proportional to $\Delta x^{2}$ and to $\sqrt{S_{0}}$ leading to extremely small time steps in cases of nearly horizontal bed with initial water depth.

It is important to remark that, when using the DW model, the greater $\Delta x$ the smaller is the difference between the DW and the KW allowable time steps.

As indicated earlier, for real applications, $\left(\lambda_{x_{i+1 / 2, j}}^{*}\right)^{ \pm}$and $\left(\lambda_{y_{i, j+1 / 2}}^{*}\right)^{ \pm}$in equation (3.14) take a value depending on the comparison of a tolerance factor $\tau_{f}$. Simulation tests show that, in the case of using the KW model, the value of $\tau_{f}$ does not affect the simulation results. In the case of using the DW model, oscillations may appear in the solution of the variable $h$ depending on the mesh cell size. A study of the appearance of these oscillations as a function of the parameter $A=h_{0} /\left(S_{0} \Delta x\right)$ was done concluding that, for $A>1$ oscillations of the order $\tau_{f}$ appeared on the solution of $h$. This parameter is related to the kinematic flow number (Ponce, 1991) indicating that, when the hyperbolic (kinematic) character of the equation is dominant the numerical method is non-oscillatory. On the other hand, when the diffusive part of the equation (Moussa and Boquillon, 2001) is dominant, oscillations of the order of $\tau_{f}$ may appear in the profile solution. An appropriate definition of the parameter $\tau_{f}$ can be used to make the oscillations negligible when compared to the values of the conserved variable. However, the presence of these oscillations may affect the variable time step making it oscillate and decreasing the model efficiency in terms of computational cost. 


\section{$\underline{\text { Appendix C }}$}

\section{Diffusive-wave and Kinematic-wave model descpription}

\section{The diffusive--wave model (DW)}

The DW model, otherwise called Non-inertia wave model (Yen and Tsai, 2001), neglects all the acceleration terms in the shallow water momentum equations (Vreugdenhil, 1994) which reduces the system of equations to:

$$
\begin{aligned}
& \frac{\partial h}{\partial t}+\frac{\partial(h u)}{\partial x}+\frac{\partial(h v)}{\partial y}=P e-i \\
& \frac{\partial}{\partial x}\left(g \frac{h^{2}}{2}\right)=g h\left(S_{0 x}-S_{f x}\right) \\
& \frac{\partial}{\partial y}\left(g \frac{h^{2}}{2}\right)=g h\left(S_{0 y}-S_{f y}\right)
\end{aligned}
$$

$h$ being the surface water depth, $u, v$ the depth averaged velocity components in the $x$ and $y$ directions respectively, $g$ the gravity acceleration, $P e$ the effective precipitation rate and $i$ the infiltration rate. $S_{0 x}$ and $S_{0 y}$ are the bed slopes in the coordinate directions,

$$
S_{0 x}=-\frac{\partial z_{b}}{\partial x}, \quad S_{0 y}=-\frac{\partial z_{b}}{\partial y}
$$

$z_{b}$ being the terrain topography elevation (see fig. 1).

The energy slopes $S_{f x}$ and $S_{f y}$ have been defined by the 2D Manning formula (Vreugdenhil, 1994): 


$$
S_{f x}=\frac{n^{2} h^{2} u \sqrt{u^{2}+v^{2}}}{h^{10 / 3}}, \quad S_{f y}=\frac{n^{2} h^{2} v \sqrt{u^{2}+v^{2}}}{h^{10 / 3}}
$$

with $n$ the Manning roughness coefficient. The water surface slopes are:

$$
S_{d x}=-\frac{\partial\left(z_{b}+h\right)}{\partial x}, \quad S_{d y}=-\frac{\partial\left(z_{b}+h\right)}{\partial y}
$$

so that equations (C.2) and (C.3) can be written as:

$$
S_{d x}=S_{f x}, \quad S_{d y}=S_{f y}
$$

and from (C.5) and (C.7):

$$
q_{x}=h u=\frac{h^{5 / 3} S_{d x}}{n \sqrt{\left|\mathbf{S}_{d}\right|}}, \quad q_{y}=h v=\frac{h^{5 / 3} S_{d y}}{n \sqrt{\left|\mathbf{S}_{d}\right|}}
$$

where $\boldsymbol{S}_{d}=\left(S_{d x}, S_{d y}\right)$. From (C.1) and (C.8), the DW model is formulated as a single differential equation in conservation form as follows:

$$
\frac{\partial h}{\partial t}+\nabla \cdot\left(\frac{h^{5 / 3}}{n \sqrt{\left|\boldsymbol{S}_{d}\right|}} \boldsymbol{S}_{d}\right)=\frac{\partial h}{\partial t}+\nabla \cdot \boldsymbol{q}=P e-i
$$


The KW model goes further and neglects all terms except the source terms in the momentum equations that forces the equality between the friction and the gravitational source terms. The definition of the bed energy slope lines as in (C.5) leads to:

$$
q_{x}=h u=\frac{h^{5 / 3} \mathrm{~S}_{0 x}}{n \sqrt{\left|\mathbf{S}_{0}\right|}}, \quad q_{y}=h v=\frac{h^{5 / 3} S_{0 y}}{n \sqrt{\left|\mathbf{S}_{0}\right|}}
$$

where $\boldsymbol{S}_{0}=\left(S_{0 x}, S_{0 y}\right)$. From (C.10) and the mass conservation equation (C.1), the KW model is formulated as a single conservation law differential equation as follows:

$$
\frac{\partial h}{\partial t}+\nabla \cdot\left(\frac{h^{5 / 3}}{n \sqrt{\left|\boldsymbol{S}_{0}\right|}} \boldsymbol{S}_{0}\right)=\frac{\partial h}{\partial t}+\nabla \cdot \boldsymbol{q}=P e-i
$$

Acknowledgements: This research has been funded by the D.G.A. (Aragon General Deputation) under research projects no PM088/2006, PI032/08 and budget application 17030 $\mathrm{G} / 5423 / 480072 / 91001$

\section{$\underline{\text { References }}$}

Abbott, M.B., Bathurst, J.C., Cunge, J.A., O’Connell, P.E. and Rasmussen, J. (1986). “An introduction to the European Hydrologic System - Systeme Hydrologique Europeen, "SHE', 2: Structure of a physically-based, distributed modeling system.” Journal of Hydrology, 87, $61-77$. 
ASCE (1996). "Hydrology Handbook-Second edition." ASCE manuals and reports on engineering practice; no. 28.

Beasely, D.B., Huggins, L.F. and Monke, E.J. (1980). “Answers: a model for watershed planning." Transactions of the ASAE 23(4), 938-944.

Bedient, P.B., Huber, W.C. and Baxter, E.V. (2008). "Hydrology and floodplain analysis. Prentice Hall." Fourth edition.

Beven, K.J. (1986). “Toward a new paradigm in hydrology.” Journal of Hydrology, 87, 393403.

Beven, K. and Kirkby, M.J. (1979). “A physically based, variable contributing area model of basin hydrology." Hydrological Sciences Bulletin, 24, 43-69.

Beven, K. and Wood, E.F. (1983). "Catchment geomorphology and the dynamics of runoff contributing areas." Journal of Hydrology, 65, 139-158.

Brustraert, W. (2005). “Hydrology, An introduction.” Cambridge University Press.

Burguete, J. and García-Navarro, P. (2001). "Efficient construction of high resolution TVD conservative schemes for equations with source terms: aplication to shallow water flows." International Journal for Numerical Methods in Fluids, 37, 209-248. 
Chow, V. T., Maidment, D.R. and Mays, L.W. (1994). "Hidrología aplicada.” Mc Graw-Hill Interamericana, S. A.

Gupta, R.S. (2008). "Hydrology and Hydraulic Systems.” Waveland press inc. Third edition.

Hargreaves, G.H. and Samani, Z.A. (1985). "Reference crop evapotranspiration from temperature." Applied Engineering in Agriculture, 1(2), 96-99.

Harmon, R.S. and Doe III, W.W. (2001). "Landscape erosion and evolution modelling." Kluwer Academic/Plenum Pubkishers. New York.

Heppner, C.S., Ran, Q., VanderKwaak, J.E. and Loague, K. (2006). “Adding sediment transport to the integrated hydrology model (InHM): Development and testing." Advances in Water Resources, 29, 930-943.

Hunter, N.M., Horrit, M.S., Bates, P.D., Wilson, M.D. and Werner, M.G.F. (2005). “An adaptative time step solution for raster-based storage cell modelling of floodplain inundation." Advances in Water Resources, vol 28, 975-991.

Ivanov, V.Y., Vivoni, E.R., Bras, R.L. and Entekhabi, D. (2004). "Preserving high resolution surface and rainfall data in operational- scale basin hydrology: a fully-distributed physicallybased aproach.” Journal of Hydrology, 298, 80-111.

Jia, Y., Ni, G., Kawahara, Y. and Suetsugi, T. (2001). "Development of WEP model and its aplication to an urban watershed." Hydrological Processes, 15, 2175-2194. 
Kazezylmaz-Alhan, C.M. and Medina Jr., M.A. (2007). "Kinematic and Diffusion Waves: Analytical and Numerical Solutions to Overland Channel Flow" Journal of Hydraulic Engineering, 133 (2), 217-228.

Lane, L.J., Nichols, M.H. and Paige, G.B. (1995). "Modelling Erosion on Hillslopes: Concepts, Theory, and data." Proceedings of the International Congress on Modelling and Simulation, 1, 1-7.

Lax, P.D. (1973). "Hyperbolic systems of conservation laws and the mathematical theory of shock waves." SIAM publications, Philadelphia.

Luo, Q. (2007). “A distributed surface flow model for watersheds with large water bodies and channel loops." Journal of Hydrology, 337, 172-186.

Mahmood, K. and Yevjevich, V. (1975). "Unsteady flow in open channels." Water Resources Publications, Fort Collins, Colorado.

Mays, L.W (2001). “Water Resources Engineering.” John Wiley \& Sons, Inc.

Michel, C. (1989). "Hydrologie apliquée aux petits bassins ruraux." Cemagref Antony, 530.

Moramarco, T., Pandolfo, C. and Singh V. P. (2008). "Accuracy of Kinematic Wave Approximation for Flood Routing. II. Unsteady Analysis." Journal of Hydrologic Engineering, 13(11), $1089-1096$. 
Morita, M. and Yen, B.C. (2002). "Modelling of Conjunctive Two-Dimensional SurfaceThree-Dimensional Subsurface Flows." Journal of Hydraulic Engineering, 128(2), 184-200.

Moussa, R. and Bocquillon, C. (2009). "On the use of the diffusive wave modelling extreme flood events with overbank flow in floodplain.” Journal of Hydrology, 374, p.116-135.

Moussa, R. and Bocquillon, C. (2001). "Fractional-step Method Solution of Diffusive Wave Equation.” Journal of Hydrologic Engineering, 6 (1), p.11-19.

Murillo, J., García-Navarro, P., Burguete, J. and Brufau, P. (2006). “A conservative 2d model of inundation flow with solute transport over dry bed." International Journal for Numerical Methods in Fluids, 52(10), 1059-1092.

Ponce, V.M. (1991). “The Kinematic Wave Controversy.” Journal of Hydraulic Engineering, $117(4), 511-524$.

Prestininzi, P. (2008). "Suitability of the diffusive model for dam break simulation: Application to a CADAM experiment.” Journal of Hydrology, 361, 172-185.

Prosser, I.P. and Rustomji, P. (2000). "Sediment transport capacity relations for overland flow." Progress in Physical Geography, 24(2), 179-193.

Russell, S., Harmon, W., and Doe III, W.W. (2001). "Landscape erosion and evolution modelling.” Kluwer Academic/Plenum Pubkishers. New York. 
Samani, Z. (2000). "Estimating solar radiation and evapotranspiration using minimun climatological data." Journal of Irrigation and Drainage Engineering, 126(4), 265-267.

Shyrley, E.D. and Lane, L.J. (1978). "A sediment yield equation from an erosion model." Proceedings of the 1978 meetings of Arizona Section of the American Water Resources Association and the Hydrology Section of Arizona Academy of Science, held in Flagstaff, Arizona, April 14-15.

VanderKwaak, J.E. (1999). "Numerical simulation of flow and chemical transport in integrated surface-subsurface hydrologic systems." $\mathrm{PhD}$ dissertation, Department of Earth and Sciences, University of Waterloo, Ontario, Canada.

Vreugdenhil, C.B. (1994). “ Numerical Methods for Shallow-Water Flow.” Kluwer Academic Publishers: Dordrecht.

Wasantha Lal, A.M. (1998). "Weighted Implicit Finite-Volume Model for Overland Flow." Journal of Hydraulic Engineering, 124(9), 941-950.

Wigmosta, M.S., Lane, L.J., A.M., Tagestad, J.D. and Coleman, A.M. (2009). "Hydrologic and Erosion Models to Assess Land Use and Management Practices Affecting Soil Erosion." Journal of Hydrologic Engineering, 14(1), 27-41.

Yen, B.C. and Tsai, C. (2001) "Noninertia wave vs. diffusion wave in flood routing." Journal of Hydrology, 244(1/2), 97-104. 
Yu, D. and Lane, S.N. (2007). "Coupling of a 2d diffusion-based flood inundation model to a $1 \mathrm{~d}$ river flow for urban flood inundation modelling." Proceedings of the Congress- IAHR, Conf $32 ; 1,30$. 